\title{
Thermal Stability of High Entropy Alloys during in Situ TEM Heating.
}

Elaf A. Anber ${ }^{1}$, Andrew C Lang ${ }^{1}$, Eric A. Lass ${ }^{2}$, Pranav Kumar Suri ${ }^{1}$, Daniel Scotto D’Antuono ${ }^{1}$, Haoyan Diao ${ }^{3}$, Peter K Liaw ${ }^{3}$, Mitra L Taheri ${ }^{1}$

1. Department of Materials Science and Engineering, Drexel University, Philadelphia, USA.

2. Materials Science and Engineering Division, National Institute of Standards and Technology, Gaithersburg, USA.

3. Department of Materials Science and Engineering, University of Tennessee Knoxville, Knoxville, USA.

Recently, high entropy alloys (HEAs) and in particular $\mathrm{Al}_{\mathrm{x}} \mathrm{CoCrFeNi}$ have received considerable attention due to its promising thermal, mechanical, and corrosion properties. This unconventional alloy design contains at least five principal elements with atomic concentrations between 5 and 35 atomic percent [1]. Instead of forming intermetallics, these alloys tend to crystallize into single phase solid solutions, and most have either face-centered cubic (FCC) or body-centered cubic (BCC) structures, due to high configurational entropy, sluggish diffusion, and severe lattice distortion [2]. Formation of secondary phases are reported in recent studies at intermediate and high annealing temperatures of the $\mathrm{Al}_{\mathrm{x}} \mathrm{CoCrFeNi} \mathrm{HEA}$, however, many of these studies focus on late stages of precipitation [3-6]. The present work is motivated by the need for a better understanding and controlling the phase stability of as-homogenized $\mathrm{Al}_{\mathrm{x}} \mathrm{CoCrFeNi}(\mathrm{x}=0.0,0.1,0.3,0.5)$ HEA at intermediate and high annealing temperatures.

In this study, we employ the in-situ TEM heating technique to track the early, intermediate and final stages of intermediate phases precipitation in $\mathrm{Al}_{\mathrm{x}} \mathrm{CoCrFeNi}$ HEA. As-homogenized HEAs were in-situ heat treated in a JEOL $2100 \mathrm{LaB}_{6}$ TEM, equipped with a high-resolution pole piece, using a Gatan heating holder at ramp rate of $0.5 \%$ s. Scanning transmission electron microscope(STEM)-equipped with energy dispersive x-ray spectroscopy (EDS) was used to study the chemical composition of the precipitates. Following STEM-EDS, selected area diffraction patterns(SAED) technique was performed to examine the crystal structure of as-homogenized and annealed samples. We find that NiAl, Co-rich and $\mathrm{Cr}$-rich precipitates formed in this alloy after undergoing in-situ TEM heating at $550{ }^{\circ} \mathrm{C}, 700{ }^{\circ} \mathrm{C}$, and $900{ }^{\circ} \mathrm{C}$ for different annealing periods. The study was coupled with phase and orientation analysis using precession electron diffraction techniques to examine the effect of grain boundary character on the precipitation of second phases. Figure 1(a-e) shows the representative high-angle annular dark-field (HAADF)-(STEM), and EDS analysis of in-situ TEM annealed $\mathrm{CoCrFeNi} \mathrm{HEAs} \mathrm{at} 700^{\circ} \mathrm{C}$ for $10 \mathrm{~min}$.

Overall, the work described provides a foundation for understanding the stability window for candidate HEAs in extreme environments. These results are discussed in the context of the growing literature comparing the ideal methods for stabilizing mechanisms in HEAs for use in high temperature environments.

References:

[1] Li et al, Acta Mater. 123, (2017), p. 285.

[2] Licavoli, J. Mater. Eng. Perform. 24, (2015), p. 3685.

[3] Kao, J. Alloys Compd. 488 (2009), p. 57.

[4] Zhang, Mater. Des. 109 (2016), p. 425. 
[5] Tang, Mater. Des. 105 (2016), p. 381.

[6] ShunT. T., Du Y. C., J. Alloys Compd. 479, (2009), p. 157.

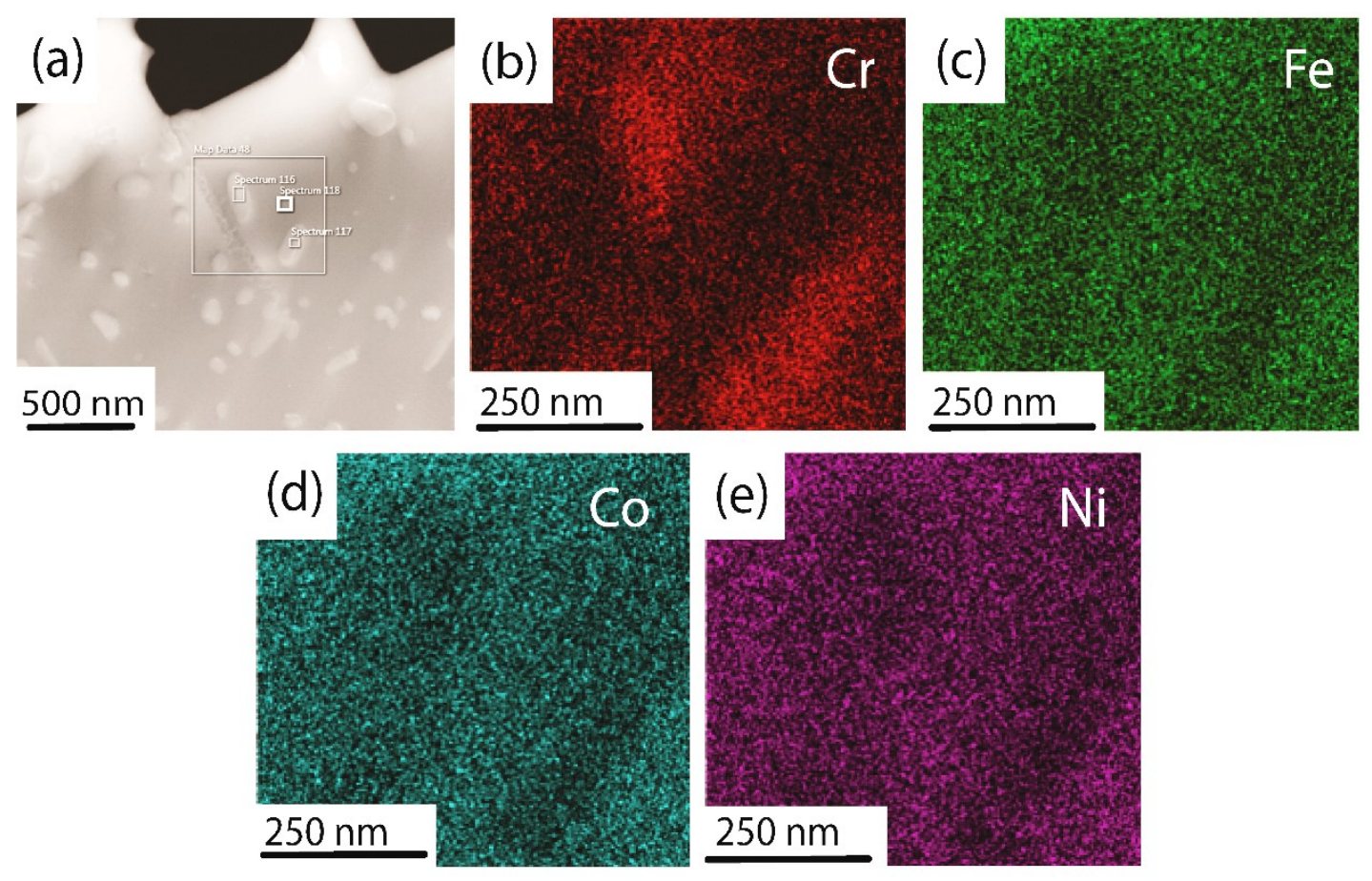

Figure 1. Representative HADAAF-STEM image of CoCrFeNi (a), EDS elemental maps show the distribution of $\mathrm{Cr}(\mathrm{b}), \mathrm{Fe}(\mathrm{c}), \mathrm{Co}(\mathrm{d})$, and $\mathrm{Ni}(\mathrm{e})$. 